\title{
Effect of Fe content on the thermal stability and dynamic mechanical behavior of $\mathrm{NdAlNiCu}$ bulk metallic glasses
}

\author{
W.H. Li ${ }^{\mathrm{a}, \mathrm{b}}$, B.C. Wei ${ }^{\mathrm{b}, *}$, Y.F. Sun ${ }^{\mathrm{b}}$, L. Xia ${ }^{\mathrm{a}}$, Y.R. Wang ${ }^{\mathrm{b}}$, Y.D. Dong ${ }^{\mathrm{a}}$ \\ a Institute of Materials, Shanghai University, Shanghai 200072, PR China \\ ${ }^{\mathrm{b}}$ National Microgravity Laboratory, Institute of Mechanics, Chinese Academy of Sciences, \\ Beijing 100080, PR China \\ Received 5 May 2004
}

\begin{abstract}
The dependence of microstructure and thermal stability on $\mathrm{Fe}$ content of bulk $\mathrm{Nd}_{60} \mathrm{Al}_{10} \mathrm{Ni}_{10} \mathrm{Cu}_{20-x} \mathrm{Fe}_{x}(0 \leq x \leq 20)$ metallic glasses is investigated by means of differential scanning calorimetry (DSC), X-ray diffraction (XRD) and high-resolution transmission electron micrograph (HRTEM). All samples exhibit typical amorphous feature under the detect limit of XRD, however, HRTEM results show that the microstructure of $\mathrm{Nd}_{60} \mathrm{Al}_{10} \mathrm{Ni}_{10} \mathrm{Cu}_{20-x} \mathrm{Fe}_{x}$ alloys changes from a homogeneous amorphous phase to a composite structure consisting of clusters dispersed in amorphous matrix by increasing Fe content. Dynamic mechanical properties of these alloys with controllable microstructure are studied, expressed via storage modulus, the loss modulus and the mechanical damping. The results reveal that the storage modulus of the alloy without $\mathrm{Fe}$ added shows a distinct decrease due to the main $\alpha$ relaxation. This decrease weakens and begins at a higher temperature with increasing Fe content. The mechanism of the effect of Fe addition on the microstructure and thermal stability in this system is discussed in terms of thermodynamics viewpoints.
\end{abstract}

(C) 2004 Elsevier B.V. All rights reserved.

Keywords: Bulk metallic glass; Glass transition; Crystallization; Dynamic mechanical thermal analysis

\section{Introduction}

Recently, bulk Nd-based amorphous alloys have received considerable interest due to their high coercivity for potential permanent magnets [1-5]. Moreover, $\mathrm{NdFeAl}$ amorphous alloys are rather unique in the different families of bulk metallic glasses (BMGs), because they do not exhibit any glass transition temperature $T_{\mathrm{g}}$ prior to crystallization temperature $T_{x}$. Depending on the thermal stability, such alloys can be subdivided into two categories by Fe content: one class of alloys is iron-free or iron-poor systems, for example $\mathrm{Nd}_{60} \mathrm{Co}_{30} \mathrm{Al}_{10}$, $\mathrm{Nd}_{60} \mathrm{Ni}_{10} \mathrm{Cu}_{10} \mathrm{Co}_{5} \mathrm{Al}_{15}$ and $\mathrm{Nd}_{60} \mathrm{Fe}_{5} \mathrm{Co}_{10} \mathrm{Cu}_{10} \mathrm{Al}_{15}$, etc. [1], showing a normal thermal stability with $T_{\mathrm{rg}}$ near 0.6 and $\Delta T_{x}$ around $40 \mathrm{~K}$. The other type of alloys is iron-rich systems, for example, $\mathrm{Nd}_{60} \mathrm{Fe}_{30} \mathrm{Al}_{10}, \mathrm{Nd}_{60} \mathrm{Fe}_{20} \mathrm{Co}_{10} \mathrm{Al}_{10}$, and

\footnotetext{
* Corresponding author. Tel.: +86-10-62614945; fax: +86-10-62615524. E-mail address: weibc@imech.ac.cn (B.C. Wei).
}

$\mathrm{Nd}_{57} \mathrm{Fe}_{20} \mathrm{Co}_{5} \mathrm{Al}_{10} \mathrm{~B}_{8}$, etc. [4,5] do not exhibit a distinct glass transition prior to crystallization starting at $T_{x}$ according to constant-rate heating DSC measurements, but exhibit an extremely high value of the ratio between the $T_{x}$ and $T_{l}$ around 0.9 . The reason for the difference between different $\mathrm{Nd}$ based systems is still unclear. In this work, the effect of $\mathrm{Fe}$ content on the glass forming ability and thermal stability of $\mathrm{Nd}_{60} \mathrm{Al}_{10} \mathrm{Ni}_{10} \mathrm{Cu}_{20}$ bulk metallic glass was systemically studied. Mechanical spectroscopy is a very suitable technique for study the thermal stability and relaxation process by determined the dynamic modulus of glassy materials. A lot of work has been reported on this subject on polymers or oxide glasses [6-9], but significantly less on BMGs [10-15]. Mechanical spectroscopy studies on $\mathrm{Zr}-$, $\mathrm{Pd}-$, and La-based BMGs have given valuable information on the kinetics of structural changes, as well as viscoelasticity and viscosity in the surpercooled liquid region [10-15]. In this study, dynamic mechanical properties of $\mathrm{Nd}_{60} \mathrm{Al}_{10} \mathrm{Ni}_{10} \mathrm{Cu}_{20-x} \mathrm{Fe}_{x}(0$ 
$\leq x \leq 20$ ) bulk metallic glasses with different microstructure are also investigated.

\section{Experimental}

Ingots with a nominal composition of $\mathrm{Nd}_{60} \mathrm{Al}_{10} \mathrm{Ni}_{10}$ $\mathrm{Cu}_{20-x} \mathrm{Fe}_{x}(x=0,3,5,7,10,15$ and 20$)$ were prepared by arc-melting of elements $\mathrm{Nd}, \mathrm{Al}, \mathrm{Ni}, \mathrm{Cu}$ and $\mathrm{Fe}$ with a purity of $99.9 \%$ in titanium-gettered argon atmosphere. Cylindrical specimens of $3 \mathrm{~mm}$ in diameter and $70 \mathrm{~mm}$ in length were prepared by suction casting into a copper mould. The structure of samples was characterized by X-ray diffraction (XRD) in a Philips PW 1050 diffractometer using $\mathrm{Cu} \mathrm{K} \alpha$ radiation. Thermal analysis was performed with a Perkin-Elmer DSC7 differential scanning calorimeter under argon atmosphere. A constant heating rate of $0.17 \mathrm{~K} / \mathrm{s}$ was employed. The dynamic mechanical properties were measured at a heating rate of $0.17 \mathrm{~K} / \mathrm{s}$ by using a dynamic mechanical thermal analyzer (Rheometric Scientific DMTA IV) in three-point bending mode. The samples for these measurements were cut from the middle part of the cylinders and had a size of $1.2 \mathrm{~mm} \times$ $3.0 \mathrm{~mm} \times 30 \mathrm{~mm}$. The applied static load was $1 \mathrm{~N}$ and the frequency for the dynamic load was $1 \mathrm{~Hz}$. The microstructural observation of the samples was performed on a JEOL JEM-2010 high-resolution transmission electron microscope (HRTEM) operated at $200 \mathrm{kV}$.

\section{Results and discussion}

Fig. 1 compares the XRD patterns of as-cast $\mathrm{Nd}_{60} \mathrm{Al}_{10} \mathrm{Ni}_{10} \mathrm{Cu}_{20-x} \mathrm{Fe}_{x}(0 \leq x \leq 20)$ samples with different $\mathrm{Fe}$ content. All as-cast alloys exhibit an XRD spectrum typical for amorphous phase without obvious crystalline peak. However, for the Fe-rich alloys ( $\mathrm{Fe} \geq 10$ ) show a more obvious broad peak at the $2 \theta$ value of about $56^{\circ}$. This suggests that the substitute of $\mathrm{Cu}$ by $\mathrm{Fe}$ changes

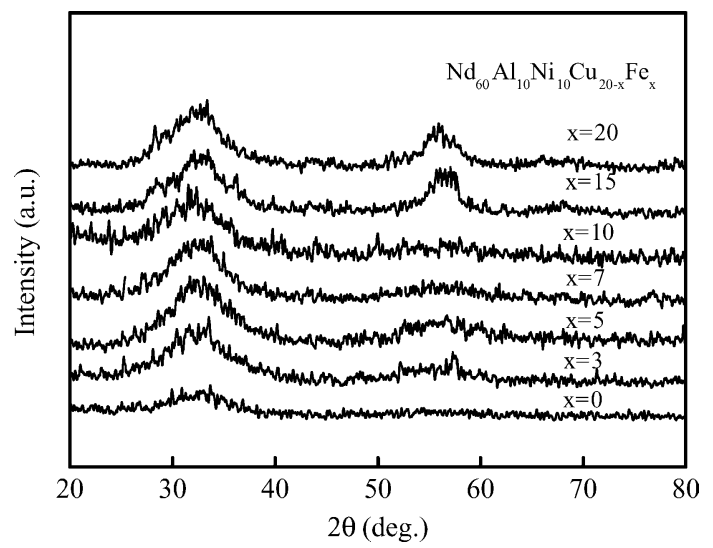

Fig. 1. XRD patterns for the as-cast $\mathrm{Nd}_{60} \mathrm{Al}_{10} \mathrm{Ni}_{10} \mathrm{Cu}_{20-x} \mathrm{Fe}_{x}(x=0,5,7$, 10,15 and 20) alloys.

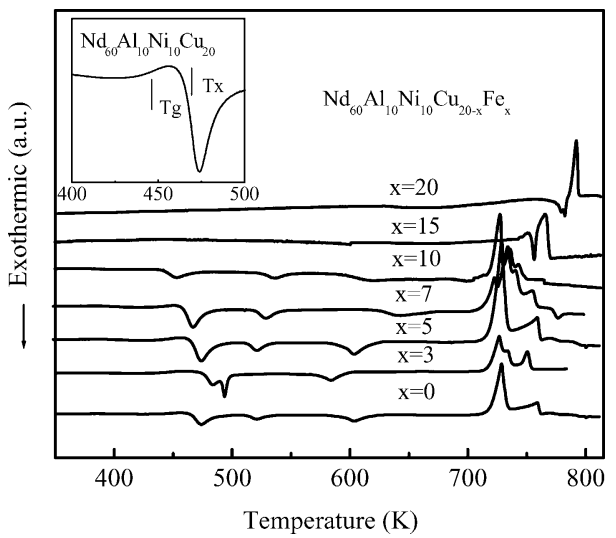

Fig. 2. DSC curves of $\mathrm{Nd}_{60} \mathrm{Al}_{10} \mathrm{Ni}_{10} \mathrm{Cu}_{20-x} \mathrm{Fe}_{x}(x=0,5,7,10,15,20)$ alloys at a heating rate of $0.17 \mathrm{~K} / \mathrm{s}$. The inset shows the enlarge part of the glass transition in $\mathrm{Nd}_{60} \mathrm{Al}_{10} \mathrm{Ni}_{10} \mathrm{Cu}_{20}$ alloy.

the short-range ordered structure in the $\mathrm{Nd}_{60} \mathrm{Al}_{10} \mathrm{Ni}_{10} \mathrm{Cu}_{20}$ metallic glass.

The thermal stability of $\mathrm{Nd}_{60} \mathrm{Al}_{10} \mathrm{Ni}_{10} \mathrm{Cu}_{20-x} \mathrm{Fe}_{x}$ amorphous alloys was evaluated by DSC measurements. Fig. 2 shows DSC traces of the $\mathrm{Nd}_{60} \mathrm{Al}_{10} \mathrm{Ni}_{10} \mathrm{Cu}_{20-x} \mathrm{Fe}_{x}$ alloys at a scanning rate of $0.17 \mathrm{~K} / \mathrm{s}$. The inset shows the details of the glass transition temperature of $\mathrm{Nd}_{60} \mathrm{Al}_{10} \mathrm{Ni}_{10} \mathrm{Cu}_{20}$ amorphous alloy. The DSC trace for the alloy without $\mathrm{Fe}$ addition exhibits an endothermic reaction beginning at $433 \mathrm{~K}$ caused by glass transition, followed by three exothermic reactions caused by crystallization with the onset temperature of 468 , 513, and $593 \mathrm{~K}$, respectively. From the DSC trace, the onset of melting in this alloy is $726 \mathrm{~K}$. Thus the supercooled liquid region $\left(\Delta T_{x}=T_{x}-T_{\mathrm{g}}\right)$ is $35 \mathrm{~K}$ and the reduced glass temperature $\left(T_{\mathrm{rg}}=T_{\mathrm{g}} / T_{\mathrm{m}}\right)$ is about 0.60 . The glass transition and three crystallization processes are also observed in the alloys with $\mathrm{Fe}=3, \mathrm{Fe}=5$ and $\mathrm{Fe}=7$ at. $\%$. The distinct glass transition followed by sharp crystallization peaks in the DSC trace is similar to the other iron-free or iron-poor Nd-based BMGs. However, in the $\mathrm{Fe}=10$ at.\% alloy, the endothermic reaction caused by glass transition is very weak, and the total enthalpy of the three crystallization reactions also decreases. An additional exothermic peak near the melting point of the alloy is observed. For the alloys with $\mathrm{Fe}=15$ and 20 at. $\%$, the three crystallization peaks and glass transition process disappear in the DSC plots. Instead, a very broad and weak exothermic peak from 630 to $750 \mathrm{~K}$ followed by a sharp exothermic peak closed to the melting point is observed. This DSC feature is similar to that of the $\mathrm{Nd}(\mathrm{Pr})$-based $\mathrm{BMG}$ with high Fe content (e.g. $\mathrm{Nd}_{60} \mathrm{Al}_{10} \mathrm{Fe}_{30}$, and $\mathrm{Nd}_{60} \mathrm{Al}_{10} \mathrm{Fe}_{20} \mathrm{Co}_{10}$, etc.), which possesses a highly relaxed amorphous structure or a composite structure, consisting of amorphous and clusters (or nanocrystals) $[16,17]$.

With the aim of clarifying the relation of the microstructure with $\mathrm{Fe}$ content in the present case, the highresolution transmission electron micrograph (HRTEM) images and nanobeam electron diffraction patterns of the $\mathrm{Nd}_{60} \mathrm{Al}_{10} \mathrm{Ni}_{10} \mathrm{Cu}_{20-x} \mathrm{Fe}_{x}(x=0,20)$ alloys are shown in 

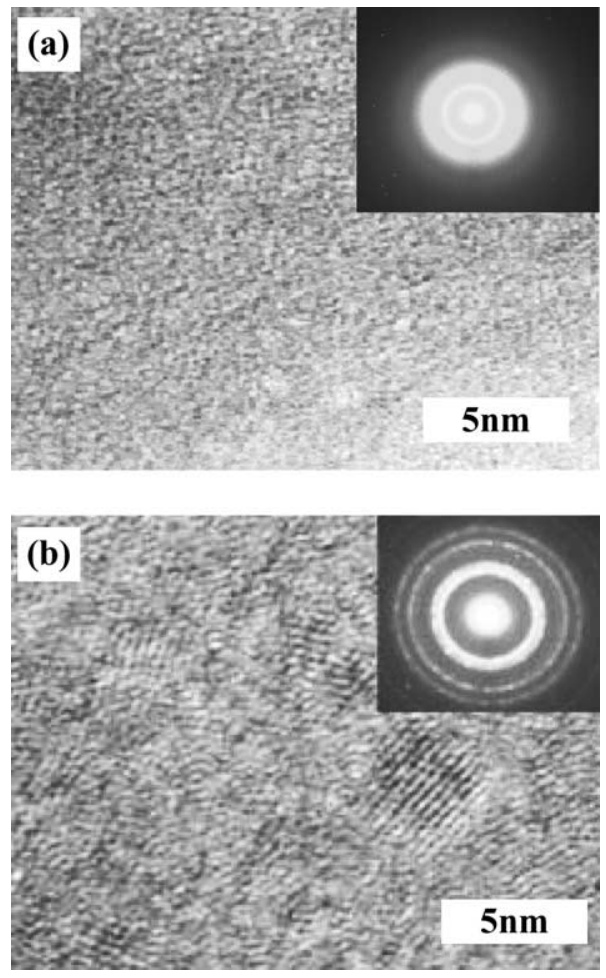

Fig. 3. HRTEM of $\mathrm{Nd}_{60} \mathrm{Al}_{10} \mathrm{Ni}_{10} \mathrm{Cu}_{20}$ alloy (a) and $\mathrm{Nd}_{60} \mathrm{Al}_{10} \mathrm{Ni}_{10} \mathrm{Fe}_{20}$ alloy (b).

Fig. 3. The Fe-free $\mathrm{Nd}_{60} \mathrm{Al}_{10} \mathrm{Ni}_{10} \mathrm{Cu}_{20}$ alloy exhibits a uniform amorphous microstructure as shown Fig. 3(a). The electron diffraction pattern is only comprised of a set of halo rings. In contrast, although no typical crystalline phase is recognized in the high Fe content alloy, there is a composite structure, i.e. nanocrystals or clusters with the size of about $5 \mathrm{~nm}$ randomly dispersed in the amorphous matrix (shown in Fig. 3(b)). The selected area electron diffraction pattern in the inset of Fig. 3(b) demonstrates this feature. Furthermore, the volume fraction of clusters and nanocrystals can be estimated about $30-40 \%$ by using image analysis technique. This microstructure feature agrees with the results of other Nd-based BMGs with high Fe content [18].

HRTEM results reveal that the microstructure of $\mathrm{Nd}_{60} \mathrm{Al}_{10} \mathrm{Ni}_{10} \mathrm{Cu}_{20-x} \mathrm{Fe}_{x}$ can change gradually from a homogeneous amorphous phase to a composite structure, consisting of dispersed clusters or nanocrystals in the amorphous matrix by increasing Fe content. It is interesting to study how this structural change affects the dynamic mechanical properties of $\mathrm{Nd}_{60} \mathrm{Al}_{10} \mathrm{Ni}_{10} \mathrm{Cu}_{20-} \mathrm{Fe}_{x}$ alloys during continuous heating. During dynamic testing, a sinusoidal stress is applied to the material, and the resulting stress developed in the material is measured and complex modulus can be determined. The complex modulus is a measure of the materials resistance to deformation. It encompasses both in-phase and outof-phase responses of the sample, from which on calculates the storage modulus, $E^{\prime}$, and the loss modulus, $E^{\prime \prime}$, respectively, $E^{*}=E^{\prime}+\mathrm{i} E^{\prime \prime}$. The elastic modulus, or storage modulus,

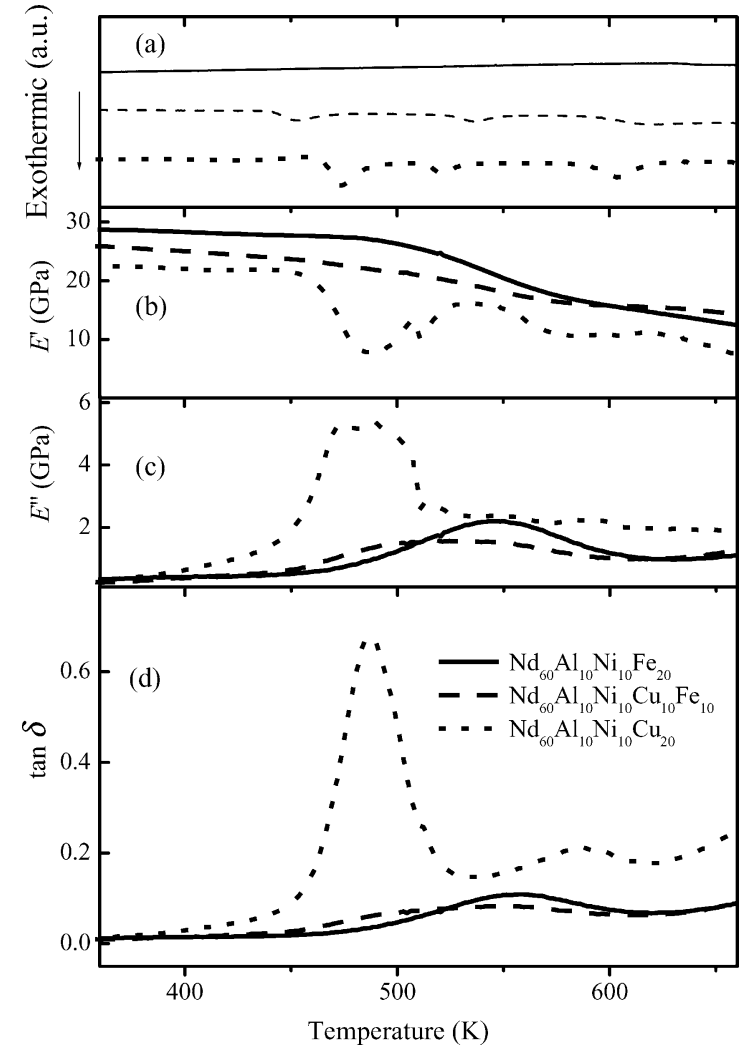

Fig. 4. DSC thermograms and temperature dependences of $E^{\prime}, E^{\prime \prime}$ and $\tan \delta$, for $\mathrm{Nd}_{60} \mathrm{Al}_{10} \mathrm{Ni}_{10} \mathrm{Cu}_{20-x} \mathrm{Fe}_{x}$ ( $x=0,10$ and 20) amorphous alloy at a heating rate of $0.17 \mathrm{~K} / \mathrm{s}$ : (a) DSC thermograms; (b) temperature dependence of $E^{\prime}$; (c) temperature dependence of $E^{\prime \prime}$; (d) temperature dependence of $\tan \delta$.

$E^{\prime}$, is a measure of the elastic energy stored and the viscous modulus, or loss modulus, $E^{\prime \prime}$, is a measure of the energy lost. The loss angle, $\tan \delta=E^{\prime \prime} / E^{\prime}$, corresponds to the internal friction. The temperature dependence of the storage modulus $\left(E^{\prime}\right)$, loss modulus $\left(E^{\prime \prime}\right)$ and the loss angle $(\tan \delta)$ in all the $\mathrm{Nd}_{60} \mathrm{Al}_{10} \mathrm{Ni}_{10} \mathrm{Cu}_{20-x} \mathrm{Fe}_{x}$ alloys are studied. The results of the alloys with $x=0,10$ and 20 are shown in Fig. 4. DSC results are also shown for comparison. For the alloy without $\mathrm{Fe}$ addition, $E^{\prime}$ decreases slightly from 22.8 to $22.0 \mathrm{GPa}$ while $E^{\prime \prime}$ and $\tan \delta$ increase gradually from room temperature to $432 \mathrm{~K}$. Subsequently, $E^{\prime}$ decreases rapidly from $21.9 \mathrm{GPa}$ at $435 \mathrm{~K}$ to $7.9 \mathrm{GPa}$ at $487 \mathrm{~K}$, which indicates the high temperature relaxation. It exhibits a strong softening at about $470 \mathrm{~K}$. The relaxation peaks of $E^{\prime \prime}$ and $\tan \delta$ are consistent to the peak of $E^{\prime}$ in this temperature range. From DSC trace it can see that the glass transition and crystallization reaction take place in this temperature range. The temperature for the glass transition and crystallization by DSC trace is in good agreement with DMTA curves. On further increasing temperature, $E^{\prime}$ enhances slightly in two temperature ranges, 486-535 and $582-617 \mathrm{~K}$, due to the crystallization processes. For the Ferich alloys, $E^{\prime}$ of the alloys are increased to 26.5 and $28.9 \mathrm{GPa}$ for $x=10$ and 20 alloy in room temperature, respectively. The softening of the $x=10$ alloy takes place at $472 \mathrm{~K}$, but in 
a quite weak behavior. The corresponding $E^{\prime \prime}$ and $\tan \delta$ exhibit a broad and weak loss peak from 472 to $615 \mathrm{~K}$. This temperature range covers the glass transition and three crystallization processes exhibited in the DSC curve. This indicates that the glass transition and three crystallization processes contribute to the energy lost in this temperature range. The dynamic mechanical behavior of $x=20$ alloy is quite similar to that of $x=10$ alloy. The softening of this alloy is also very weak, but starts at a higher temperature, $490 \mathrm{~K}$. A broad loss peak from 490 to $615 \mathrm{~K}$ is observed in $E^{\prime \prime}$ and $\tan \delta$ curve. This suggests that there are also a series of glass transition and crystallization process occurred in this temperature range in the high $\mathrm{Fe}$ content alloy.

Normally, glass transition temperature has a weak dependence on composition in the same alloy system [19]. The present fully glassy $\mathrm{Nd}_{60} \mathrm{Al}_{10} \mathrm{Ni}_{10} \mathrm{Cu}_{20}$ alloy exhibits a remarkable $\alpha$ relaxation, characteristic of amorphous materials. In higher Fe content alloys, although the size and volume fraction of clusters and nanocrystals increase with increasing Fe content, there is still a large fraction of amorphous phase existed in the alloy (e.g. $>60 \%$ in the $x=20$ alloy, Fig. 3(b)). However, a quite weak softening caused by $\alpha$ relaxation is observed in the alloy with $\mathrm{Fe}$ content lager than $10 \%$ (Fig. 4). This may be caused by the increase of viscosity due to the dispersed clusters and nanocrystals in the higher Fe content alloys. In the glassy state at the low frequency, internal friction is given by the formula, $\tan \delta=G / 2 \pi f \eta$, where $G$ is the shear modulus, $f$ the measuring frequency, and $\eta$ the viscosity [20]. Dispersed nanocrystals or clusters of rich-iron alloys greatly enhance the viscosity of glassy state alloys, and thereby reduce the energy lost. The increase of viscosity in the undercooled state also causes the atom diffusion and rearrange are more difficult during the process of glass transition and crystallization, and increase $T_{\mathrm{g}}$ and $T_{x}$ revealed by $E^{\prime \prime}$ and $\tan \delta$ broad peaks.

The substitute of $\mathrm{Cu}$ by $\mathrm{Fe}$ in the present alloy system reduced the volume fraction of amorphous phase, and on the other hand, it also changes the crystallization processes of $\mathrm{Nd}_{60} \mathrm{Al}_{10} \mathrm{Ni}_{10} \mathrm{Cu}_{20}$ alloy. The glass transition and first three crystallization processes become weaker and weaker with increasing Fe content, and an additional crystallization is observed near the melting temperature in the $x>10$ alloys. In DMTA results, the separated $E^{\prime \prime}$ and $\tan \delta$ loss peaks caused by glass transition and crystallization processes in the $\mathrm{Fe}$ poor alloys gradually change into one broad loss peak in the high Fe alloys. There is no reflection phenomenon in DSC traces for $x=15$ and 20 alloys corresponding to this temperature range, in which loss peaks are observed in $E^{\prime \prime}$ and $\tan \delta$ curves. This indicates the chemical composition of the amorphous phase changed with increasing $\mathrm{Fe}$ content. In order to clarify this effect, one has to consider the features of the $\mathrm{Nd}-\mathrm{Fe}$ and $\mathrm{Nd}-\mathrm{Cu}$ binary phase diagram [21]. The mixing heat calculated by using the Miedema model [22] is $+1 \mathrm{~kJ} / \mathrm{mol}$ for $\mathrm{Nd}-\mathrm{Fe}$ and $-56 \mathrm{~kJ} / \mathrm{mol}$ for $\mathrm{Nd}-\mathrm{Cu}$ alloys, respectively. This means that $\mathrm{Nd}$ and $\mathrm{Fe}$ atoms are positively mixed, and tend to repulse each other during copper mould cooling. The major components in the BMG forming systems normally show a large negative mixing heat [23-25]. The positive mixing heat of $\mathrm{Nd}$ and $\mathrm{Fe}$ in the present system may lead to a complicated amorphous phase separation. In other words, by increasing Fe content in the present system, amorphous phases with different chemical composition form during cooling in the high $\mathrm{Fe}$ content alloys, in addition to the decrease of total amorphous fraction. The amorphous phase separation was also indicated by others in the high Fe content Nd-based BMG through low temperature magnetic measurements [26]. The glass transition and crystallization processes take place gradually, but has little thermal effect, as each amorphous phase has a quite small volume fraction. However, dynamic mechanical properties are sensitive to these weak processes in the high $\mathrm{Fe}$ content $\mathrm{Nd}_{60} \mathrm{Al}_{10} \mathrm{Ni}_{10} \mathrm{Cu}_{20-x} \mathrm{Fe}_{x}$ system.

\section{Conclusions}

In conclusion, bulk amorphous alloys with good glassforming ability for $\mathrm{NdAlNiCuFe}$ systems have been prepared by copper mould casting. X-ray diffraction patterns and HRTEM images show a homogeneous amorphous phase in the Fe-free alloy, while, nanocrystals or clusters dispersed in the amorphous matrix in the high Fe content alloys. The room temperature elastic modulus of the alloys increases gradually with increasing Fe content. During constant heating, Fe-poor alloy exhibits a strong softening due to glass transition, and three loss energy peaks caused by crystallization processes in dynamic mechanical measurements. While, only one broad and weak loss peak caused by glass transition and crystallization is observed in the high $\mathrm{Fe}$ content alloys. The effect of $\mathrm{Fe}$ content on the thermal stability of the present $\mathrm{NdAlNiCuFe}$ system is thought due to the positive heat of mixing between $\mathrm{Nd}$ and Fe elements.

\section{Acknowledgements}

The authors are grateful for the financial support of the National Science Foundation of China (50101012 and 50031010).

\section{References}

[1] Y. He, C.E. Price, S.J. Poon, G.J. Shiflet, Phil. Mag. Lett. 70 (1994) 213.

[2] A. Inoue, T. Zhang, A. Takeuchi, W. Zhang, Mater. Trans. JIM 37 (1996) 636

[3] A. Inoue, A. Takeuchi, T. Zhang, Metall. Mater. Trans. 29A (1998) 1779.

[4] B.C. Wei, Y. Zhang, Y.X. Zhuang, D.Q. Zhao, M.X. Pan, W.H Wang, W.R. Hu, J. Appl. Phys. 89 (2001) 3529.

[5] R.J. Ortega-Hertogs, A. Inoue, K.V. Rao, Scripta Mater. 44 (2001) 1333-1336.

[6] J. Debast, P. Gilard, Phys. Chem. Glasses 4 (1963) 117. 
[7] J.J. Mills, J. Non-Cryst. Solids 14 (1974) 255.

[8] R.D. Corsaro, Phys. Chem. Glasses 17 (1976) 128.

[9] J. Perez, Polymer 29 (1988) 483.

[10] M.L. Lee, Y. Li, Y.P. Feng, W.C. Canter, Phys. Rev. B 67 (2003) 132201.

[11] T.A. Waniuk, R. Busch, A. Masuhr, W.L. Johnson, Acta Mater. 46 (1998) 5229.

[12] O.P. Bobrov, V.A. Khonik, S.N. Laptev, M.Y. Yazvitsky, Scripta Mater. 49 (2003) 255.

[13] Y. Hiki, T. Yagi, T. Aida, S. Takeuchi, J. Alloy Compd. 355 (2003) 42.

[14] K. Schröter, G. Wilde, R. Willnecker, M. Weiss, K. Samwer, E. Donth, Eur. Phys. B B5 (1998) 1.

[15] J.M. Pelletier, B. Van de Moortèle, I.R. Lu, Mater. Sci. Eng. A 336 (2002) 190.

[16] K.M. Flores, R.H. Dauskart, Acta Mater. 49 (2001) 2527.
[17] H.Z. Kong, J. Ding, L. Wang, T. White, Y. Li, J. Phys. D: Appl. Phys. 35 (2002) 423.

[18] Z. Zhang, L. Xia, R.J. Wang, B.C. Wei, M.X. Pan, W.H. Wang, Appl. Phys. Lett. 81 (2002) 4371.

[19] H.S. Chen, in: F.E. Luborsky (Ed.), Amorphous Metallic Alloys, Buttersworth, London, 1983, p. 169.

[20] A.S. Nowick, B.S. Berry, Anelastic Relaxation in Crystalline Solids, Academic Press, New York, 1972.

[21] T.B. Massalski, Binary Alloy Phase Diagrams, ASM International, Materials Park, OH, 1992

[22] A.R. Miedema, R. Boorn, F.R. De Boer, J. Less-common Met. 41 (1975) 283.

[23] D. Turnbull, Contemp. Phys. 10 (1969) 473-488.

[24] W.L. Johnson, MRS Bull. 24 (1999) 42-56.

[25] A. Inoue, Mater. Sci. Eng. 226-228 (1997) 357-363.

[26] B.C. Wei, W.H. Wang, M.X. Pan, Phys. Rev. B 64 (2001) 012406. 